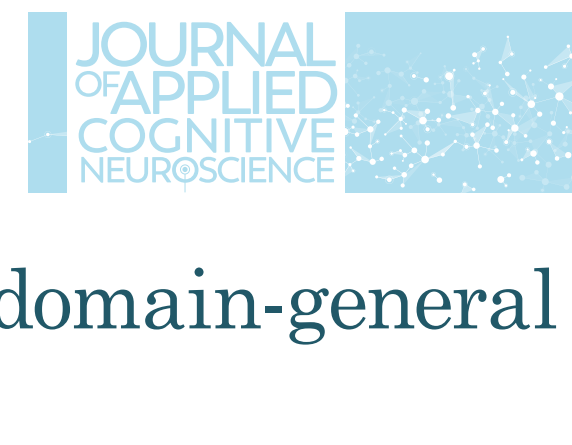

\title{
Interaction between domain-specific and domain-general abilities in math's competence
}

DOI: https://doi.org/10.17981/JACN.1.1.2020.08

\section{Sandra Torresi ${ }^{1}$}

\author{
${ }^{1}$ Universidad Favaloro. \\ Buenos Aires (Argentina)
}

Correspondence:

\section{Sandra Torresi}

Universidad de Favaloro.

Buenos Aires (Argentina)

E mail: sptorresi@gmail.com

\section{Abstract}

This article is an approach to some viewpoints about interactions between domain-specific and general cognitive tools involved in the development of mathematical competence. Many studies report positive correlations between the acuity of the numerical approximation system and formal mathematical performance, while another important group of investigations have found no evidence of a direct connection between non-symbolic and symbolic numerical representations. The challenge for future research will be to focus on correlations and possible causalities between non-symbolic and symbolic arithmetic skills and general domain cognitive skills in order to identify stable precursors of mathematical competence.

Keywords: Numerical cognition; cognitive development; approximate number system; working memory

\section{Interacción entre habilidades de dominio específico y dominio general en la competencia matemática}

\section{Resumen}

Este artículo es una aproximación a diferentes puntos de vista acerca de la interacción entre las habilidades cognitivas de dominio específico y general involucradas en el desarrollo de la competencia matemática. Muchos estudios reportan correlaciones positivas entre la agudeza del sistema de aproximación numérica y el desempeño matemático formal, mientras que otro grupo importante de investigaciones no han hallado evidencias de una conexión directa entre las representaciones numéricas no simbólicas y las simbólicas. El desafío para las futuras investigaciones será focalizar en correlaciones y posibles causalidades entre las habilidades aritméticas no simbólicas, las simbólicas y las habilidades cognitivas de dominio general con el propósito de identificar precursores estables de la competencia matemática.

Palabras clave: Cognición numérica; desarrollo cognitivo; sistema de aproximación numérica; memoria de trabajo; precursores 


\section{INTRODUCTION}

Natural numbers are a critical tool for almost all human cultural achievements, they are everywhere and we deeply depend on them so, a central question for science is how they arise in our lives... which are the foundations that support numerical thinking.

Cognitive development depends on two types of essential tools, domain-specific and domain-general processes (Butterworth, 2019) and the way these abilities co-develop is crucial for understanding learning in general, and math learning in particular.

Domain-specific representations guide and constraint the cultural acquisition of novel representations (Carey, 2009; Piazza \& Izard, 2009). The core knowledge systems are universally shared independently of formal education and engaged throughout lifetime (Spelke, 2017). For numbers, the neurocognitive startup tool are two preverbal and non-symbolic systems for numerical quantification to of the environment: the Approximate Number System (ANS) and the Object Tracking System (OTS) (Piazza \& Izard, 2009; Piazza, 2010). But this nonverbal number sense may not be enough to develop verbal and exact math competencies and domain-general abilities could be involved.

Domain-general cognitive tools are necessary in a wide variety of tasks and refer to higher order cognitive variables that can predict the performance of several competencies (Fritz, Haase \& Räsänen, 2019), for instance, Working Memory (WM) (Blankenship, Keith, Calkins \& Bell, 2018) and Processing Speed (PS) (Clark, Nelson, Garza, Sheffield, Wiebe \& Espy, 2014) or language (Butterworth, 2019).

\section{Domain-specific tools: ANS and OTS}

The Approximate Number System (ANS) enables humans to represent and manipulate quantities in an approximate manner, it means that encodes an imprecise estimate of the numerical magnitude of a set (Nieder \& Dehane, 2009; Nieder, 2019). This ancient and evolutionary number sense is shared with non-human animals and primates (Cantlon \& Brannon, 2007) and is present from the very beginning, long before the acquisition of symbolic number.

Newborns are sensitive to the abstract numerical attributes of the environment and reacts to the cardinal values of sets presented in all sensory modalities, auditory or tactile, not only in a visual way (Anobile, Cicchini \& Burr, 2016; Izard, Sann, Spelke \& Streri, 2009) and they are able to discriminate between sets irrespective of the physical properties: surface area, density or contour length (Matejko \& Ansari, 2016).

ANS increases in acuity through childhood until around 30 years old (Halberda, Ly, Wilmer, Naiman \& Germine, 2012) and varies across individuals (Piazza \& Izard, 2009). ANS acuity is assessed with simple approximation number tasks of comparison of two sets, the performance depends on the ratio between the quantities. Because of ANS imprecision close quantities are more difficult to discriminate.

To solve an everyday decision making anytime counting is not possible, ANS representation is activated during both nonsymbolic and symbolic approximations (Libertus, Odic, Feigenson \& Halberda, 2020), the two systems remain intimately linked and mutually interact with each other. 
The second core tool involved in number processing is the Object Tracking System, OTS (Dehaene, 2011), a visuospatial objectbased attention system that allows a quick, effortless apprehension up to 4 items called subitizing (Ashkenazi, Mark-Zigdon \& Henik, 2013). This is a mechanism to enumerate the number of sets at a glance and with high accuracy (Butterworth, 2019; Revkin, Piazza, Izard, Cohen \& Dehaene, 2008) without counting. Similar to ANS, OTS varies across individuals and develops in a short period of time and babies reach the adult (like limit of 3-4 items in the first year of life). It's most important constraint is that it's limited to a small set (Piazza, 2010), for larger sets exact and serial but slower counting is the only possible mechanism because larger numbers can't be tracked (Nieder, 2019). Subitizing is a precursor of counting and symbolic representations and the acquisition of a mental number line spatially left-right organization (Dehaene, 2011).

The approximate number system and subitizing are complementary mechanisms of the number sense. Together, enable the comprehension of cardinality and ordinality (Rapin, 2016). Similar to ANS, OTS varies across individuals and develops in a short period of time and babies reach the adult (like limit of 3-4 items in the first year of life). Around 4 years old, are assembled and children understand that sets may have a precise number, so 15 is a different concept from 13 (Dehaene, 2011).

The relation between ANS acuity and mathematical performance has been explored intensively but results remain unclear yet. In fact, several studies have shown that ANS acuity is meaningfully related to mathematical achievement and have also suggested that individual differences in this non-symbolic system pre- dict symbolic mathematical skills (Libertus, Feigenson \& Halberda, 2011; Bonny \& Lourenco, 2013). For instance, on magnitude comparison tasks typical development children outperforming math learning disabilities children (Desoete, Ceulemans, De Weerdt \& Pieters, 2012). So, ANS acuity may be helpful in designing diagnostic and intervention tools (Park \& Branon, 2014).

ANS and the symbolic number system rely on each other in a sort of continuity of both representations, the way to acquire the meaning of symbolic numbers is linking with the preexisting innate representations of numbers. So, ANS may constitute the semantic foundation for the symbolic numbers (Dehaene, 2011; Mazzocco, Feigenson \& Halberda, 2011).

Three meta-analyses confirm the positive relation between non-symbolic number acuity and math ability (Chen \& Li, 2014; Fazio, Bailey, Thompson \& Siegler, 2014; Schneider et al., 2016); however, many others studies failed to identify the relation between them (Chu, vanMarle \& Geary, 2015; Vanbinst, Ghesquiere \& Smedt, 2012; Zhou, Wei, Zhang, Cui \& Chen, 2015).

Bugden \& Ansari (2011) suggest that ANS acuity wouldn't be the foundation for early mathematical development but the basic symbolic competencies, numerals, number words and the relations among them. The notion of a direct link from non-symbolic to symbolic is challenged by the hypothesis that number symbols are not necessarily inextricably tied to non-symbolic quantities. Resents findings indicate that symbolic and non-symbolic abilities show different developmental trajectories in the first year of schooling but not a unidirectional relationship (Matejko \& Ansari, 2016) and even divergent patterns of representation at the neural level (Goffin \& Vogel, Slipenkyj \& Ansari, 2020). 
Possibly, both ANS acuity and the understanding of number symbols independently contribute to math learning (Fazio et al., 2014). ANS may facilitate children's explicit understanding of cardinal value and indirectly may influence early mathematical learning (Chu et al., 2015).

Undoubtedly, the experience with numbers and arithmetic of formal education enhanced the accuracy in the development of ANS (Lindskog, Winman \& Juslin, 2014). For instance, there's evidence of higher ANS acuity in individuals who had formal education experience than without formal education or after ANS training (Nys et al., 2013; Honoré \& Noel, 2016). Indeed, what it's relevant for teaching math is that ANS is refined through practice with the symbolic number system (Matejko \& Ansari, 2016) and that acuity facilitates the acquisition of cardinal principle (Nieder, 2019), the core concept of succession of natural numbers.

Two concepts must be defined to avoid confusions: cardinality refers to set size, the last number produced when counting the set: 1, 2, 3, 4.. 5 (Szkudlarek \& Brannon, 2017), symbolic number includes the Arabic code and verbal code representations: 5 and five.

\section{Domain-general tools: the case of WM}

According to Carey (2009) and Szkudlarek \& Brannon (2017) improving math depends on a multifaceted approach so, ANS acuity is a foundational skill but insufficient. Many studies focused on different domain general abilities as predictors of children individual mathematical achievement: fluid intelligence and working memory (Blankenship et al., 2018; Geary, 2011; Xenidou-Dervou et al., 2018), processing speed (Clark et al.,
2014; Kuzmina, Tikhomirova, Lysenkova \& Malykh, 2020), vocabulary and word recall (Purpura \& Ganley, 2014), inhibitory control (Gilmore et al., 2013) or in a combination of three: intelligence, central executive and reading achievement in a seven-year longitudinal study (Geary, Nicholas, Li \& Sun, 2017).

Working Memory (WM) has shown to be a strong longitudinal predictor of various mathematical skills (Hornung, Schiltz, Brunner \& Martin, 2014; Xenidou-Dervou et al., 2018). According to Baddeley (2012), WM is an attention-driven multicomponent cognitive construct, an active system for temporal storing and processing information in an online manner at service of complex cognitive tasks. The system includes four components: a) Central Executive (CE), the most complex, an attentional system which monitors, controls and regulates the workings of the others and is activated when visual, spatial or phonological elements need to be manipulated, b) a Buffer Store (BS) for integrating information from a range of sources into a multidimensional code, c) a Phonological Loop (PL) a brief store of phonological elements together with a means of maintaining information by vocal or subvocal rehearsal, and d) a Visuospatial Sketchpad (VSSP) for storing spatial and visual information.

WM span is considered essential to math skill but this seems to be content-specific: visuospatial rather than verbal WM skills correlate with math achievement (Clearman, Klinger \& Szücs, 2017). In a recent systematic review, Allen, Higgins \& Adams (2019) confirmed an evident positive effect of visuospatial WM on mathematics attainments and suggested to take into consideration the type of VSSP involved. It is possible to identify the individual con- 
tribution of each component of the WM underlying different tasks (Fanari, Meloni \& Massida, 2019), for instance, CE will be necessary in counting backward in twos from a certain number, whereas simply repeating the same number would not because it's related to another component, the PL. In the case of atypical math development, researchers found difficulties in spatial WM tasks performance but not in visual tasks (Mammarella, Caviola, Giofrè \& Szücs, 2018).

\section{Conclusions}

In a way of reconciling discrepant findings about precursors of math competence, research proposes that interventions should focus on domain-specific skills but also general cognitive abilities (Träff, Östergren \& Skagerlund, 2020) as apparently, they contribute to distinct aspects during math growth. Indeed, both are implied and interact in the early numeracy (LeFevre et al., 2010) with different weights and in different moments and perhaps different resources for similar tasks (Fanari et al., 2019; Hornung et al., 2014).

Siemmann \& Petermann (2018) suggested an integral model that could help understanding learning math and identifying children at risk of struggling with mathematics. They describe three factors for arithmetic development: a domain-specific number sense, the foundation on which arithmetic development rest, a scaffold of domain-general skills that assist in linking abstract numerosity with symbolic representation, and tools, the early number competencies: ordinality, cardinality, counting that are involved in arithmetic.

This body of novel concepts from cognitive neuroscience on precursors of math development should be considered a valuable contribution for educational interventions (Hellstrand, Korhonen, Räsänen, Linnanmaki \& Aunio, 2020). It's extremely important that educators improve their knowledge about factors related to healthy math competence. Teachers need this evidencebased guidance to make educational decisions about what to teach, why, how and when.

\section{REFERENCES}

Anobile, G., Cicchini, G. M. \& Burr, D. C. (2016). Number as a Primary Perceptual Attribute: A Review. Perception, 45(1-2), 5-31. https://doi. org/10.1177/0301006615602599

Ashkenazi, S., Mark-Zigdon, N. \& Henik, A. (2013). Do subitizing deficits in developmental dyscalculia involve pattern recognition weakness? Developmental Science, 16(1), 35-46. https://doi.org/10.1111/j.14677687.2012.01190.x

Allen, K., Higgins, S. \& Adams, J. (2019). The relationship between visuospatial working memory and mathematical performance in school-aged children: a systematic review. Educational Psychology Review, 31, 1-23. https://doi. org/10.1007/s10648-019-09470-8

Baddeley, A. D. (2012). Working memory: theories, models, and controversies. Annual Review of Psychology, 63, 1-29. https://doi.org/10.1146/annurevpsych-120710-100422

Blankenship, T. L., Keith, K., Calkins, S. D. \& Bell, M. A. (2018). Behavioral performance and neural areas associated with memory processes contribute to math and reading achievement in 6-year- old children. Cognitive Development, 45, 141-151, https://doi. org/10.1016/j.cogdev.2017.07.002 
Bonny, J. W. \& Lourenco, S. F. (2013). The approximate number system and its relation to early math achievement: Evidence from the preschool years. Journal of Experimental Child Psychology, 114(3), 375-388. https://doi. org/10.1016/j.jecp.2012.09.015

Butterworth, B. (2019). Dyscalculia: from Science to Education. New York: Taylor $\&$ Francis.

Bugden, S. \& Ansari, D. (2011). Individual differences in children's mathematical competence are related to the intentional but not the automatic processing of Arabic numerals. Cognition, 118(1), 32-44. https://doi.org/10.1016/j.cognition.2010.09.005

Cantlon, J. F. \& Brannon, E. M. (2007). Basic math in monkeys and college students. PLoS Biology, 5(12), 29122919. https://doi.org/10.1371/journal. pbio.0050328

Carey, S. (2009). The Origin of Concepts. New York: Oxford Scholarship. https://doi.org/10.1093/acprof:oso/97801 95367638.001 .0001

Chen, Q. \& Li, J. (2014). Association between individual differences in nonsymbolic number acuity and math performance: A meta-analysis. Acta Psychologica, 148, 163-172. http://doi. org/10.1016/j.actpsy.2014.01.016

Chu, F. W., vanMarle, K. \& Geary, D. (2015). Early numerical foundations of young children's mathematical development. Journal of Experimental Child Psychology, 132, 205-212. http://dx.doi. org/10.1016/j.jecp.2015.01.006

Clark, C. A. C., Nelson, J. M., Garza, J., Sheffield, T. D., Wiebe, S. A. \& Espy, K. A. (2014). Gaining control: Changing relations between executive control and processing speed and their relevance for mathematics achievement over course of the preschool period. Frontiers in Psychology, 5, 1-15. https://doi. org/10.3389/fpsyg.2014.00107
Clearman, J., Klinger, V. \& Szücs, D. (2017). Visuospatial and verbal memory in mental arithmetic. Quarterly Journal of Experimental Psychology, 70(9), 18371855. https://doi.org/10.1080/17470218.2 016.1209534

Dehaene, S. (2011). The Number Sense. New York: Oxford University Press.

Desoete, A., Ceulemans, A., De Weerdt, F. \& Pieters, S. (2012). Can we predict mathematical learning disabilities from symbolic and non-symbolic comparison tasks in kindergarten? Findings from a longitudinal study. British Journal of Educational Psychology, 82(1), 64-81. https:// doi.org/10.1348/2044-8279.002002

Fanari, R., Meloni, C. \& Massidda, D. (2019). Visual and Spatial Working Memory Abilities Predict Early Math Skills: A Longitudinal Study. Frontiers in Psychology, 10, 1-9. https://doi.org/10.3389/ fpsyg.2019.02460

Fazio, L. K., Bailey, D. H., Thompson, C.A. \& Siegler, R.S. (2014). Relations of different types of numerical magnitude representations to each other and to mathematics achievement. Journal of Experimental Child Psychology, 123, 53-72. http:// doi.org/10.1016/j.jecp.2014.01.013

Fritz, A., Haase, V. \& Räsänen, P. (Eds.) (2019). International Handbook of Mathematical Learning Difficulties. From the Laboratory to the Classroom. Cham: Springer.

Geary, D. (2011). Cognitive predictors of achievement growth in mathematics: A five-year longitudinal study. Developmental Psychology, 47(6), 1539-1552. https://doi.org/10.1037/a0025510

Geary, D., Nicholas, A., Li, Y. \& Sun, J. (2017). Development change in the influence of domain-general abilities and domain-specific knowledge on mathematics achievement: an eight-year longitudinal study. Journal of Educational Psychology, 109(5), 680-693. https://doi. org/10.1037/edu0000159 
Gilmore, C., Attridge, N., Clayton, S., Cragg, L., Johnson, S., Marlow, N., Simms, V. \& Inglis, M. (2013). Individual differences in inhibitory control, not non-verbal number acuity, correlate with mathematics achievement. PLoS One, 8(6), 1-9. https://doi.org/10.1371/journal. pone.0067374

Goffin, C., Vogel, S. E., Slipenkyj, M. \& Ansari, D. (2020). A comes before B, like 1 comes before 2 . Is the parietal cortex sensitive to ordinal relationships in both numbers and letters? An fMRI-adaptation study. Human Brain Mapping, 41(6), 1591-1610. https://doi. org/10.1002/hbm.24897

Halberda, J., Ly, R., Wilmer, J. B., Naiman, D. Q. \& Germine, L. (2012). Number sense across the lifespan as revealed by a massive Internet-based sample. Proceedings of the National Academy of Sciences, 109(28), 11116-11120. http:// doi.org/10.1073/pnas.1200196109

Hellstrand, H., Korhonen, J., Räsänen, P., Linmmanmaku, K. \& Aunio, P. (2020). Reliability and validity evidence of the early numeracy test for identifying children at risk for mathematical learning difficulties. International Journal of Educational Research, 102, 1-10. https:// doi.org/10.1016/j.ijer.2020.101580

Honoré, N. \& Noël, M. P. (2016). Improving preschoolers' arithmetic through number magnitude training: The impact of non-symbolic and symbolic training. PloS ONE, 11(11), 1-22. https://doi. org/10.1371/journal.pone.0166685

Hornung, C., Schiltz, C., Brunner, M. \& Martin, R. (2014). Predicting firstgrade mathematics achievement: the contributions of domain-general cognitive abilities, nonverbal number sense, and early number competence. Frontiers in Psychology, 5, 1-18 https://doi. org/10.3389/fpsyg.2014.00272
Izard, V., Sann, C., Spelke E. S. \& Streri, A. (2009). Newborn infants perceive abstract numbers. Proceedings of the National Academy of Sciences of the United States of America, 106(25), 10382-1038. https://doi.org/10.1073/ pnas.0812142106

Kuzmina, Y., Tikhomirova, T., Lysenkova, I. \& Malykh, S. (2020). Domain-general cognitive functions fully explained growth in nonsymbolic magnitude representation but not in symbolic representation in elementary school children. PLoS ONE, 15(2), 1-23. https://doi.org/10.1371/journal. pone.0228960

LeFevre, J. A., Fast, L., Skwarchuk, S. L., Smith-Chant, B. L., Bisanz, J., Kamawar, D. \& Penner-Wilger, M. (2010). Pathways to mathematics: Longitudinal predictors of performance. Child Development, 81(6), 1753-1767. https://doi.org/10.1111/ j.1467-8624.2010.01508.x

Libertus, M. E., Feigenson, L. \& Halberda, J. (2011). Preschool acuity of the approximate number system correlates with school math ability. Developmental Science, 14(6), 1292-300. https://doi.org/10.1111/ j.1467-7687.2011.01080.x

Libertus, M. E., Odic, D., Feigenson, L. \& Halberda, J. (2020). Effects of Visual Training of Approximate Number Sense on Auditory Number Sense and School Math Ability. Frontiers in Psychology, 11, 1-16. https://doi. org/10.3389/fpsyg.2020.02085

Lindskog, M., Winman, A. \& Juslin, P. (2014). The association between higher education and approximate number system acuity. Frontiers in Psychology, 5, 1-10. https://doi.org/10.3389/ fpsyg.2014.00462 
Mammarella, I. C., Caviola, S., Giofrè, D. \& Szücs, D. (2018). The underlying structure of visuospatial working memory in children with mathematical learning disability. British Journal of Developmental Psychology, 36(2), 220-235. https://doi. org/10.1111/bjdp.12202

Matejko, A. A. \& Ansari, D. (2016). Trajectories of Symbolic and Non-symbolic Magnitude Processing in the First Year of Formal Schooling. PLOS ONE, 11(3), 1-15. http://doi.org/10.1371/journal.pone.0149863

Mazzocco. M. M., Feigenson, L. \& Halberda, J. (2011). Impairs acuity of the approximate number system underlines mathematical learning disability (Dyscalculia). Child Development, 82(4), 1224-1237. https://doi. org/10.1111/j.1467-8624.2011.01608.x

Nieder, A. (2019). A brain for numbers. The biology of the number instinct. Cambridge: MIT Press.

Nieder, A. \& Dehaene, S. (2009). Representation of number in the brain. Annual Review of Neuroscience, 32, 185208. https://doi.org/10.1146/annurev. neuro.051508.135550

Nys, J., Ventura, P., Fernandes, T., Querido, L., Leybaert, J. \& Content, A. (2013). Does math education modify the approximate number system? A comparison of schooled and unschooled adults. Trends in Neuroscience and Education. 2(1), 13-22. https://doi. org/10.1016/j.tine.2013.01.001

Park, J. \& Brannon, E. M. (2014). Improving arithmetic performance with number sense training: An investigation of underlying mechanism. Cognition, 133(1), 188-200. https://doi. org/10.1016/j.cognition.2014.06.011
Piazza, M. (2010). Neurocognitive startup tools for symbolic number representations. Trends in Cognitive Sciences, 14(12), 542-551. https://doi. org/10.1016/j.tics.2010.09.008

Piazza, M. \& Izard, V. (2009). How humans count: numerosity and the parietal cortex. The Neuroscientist, 15(3), 261-273. https://doi. org/10.1177/1073858409333073

Purpura, D. J. \& Ganley, C. M. (2014). Working memory and language: Skillspecific or domain-general relations to mathematics? Journal of Experimental Child Psychology, 122, 104-121. https:// doi.org/10.1016/j.jecp.2013.12.009

Rapin, I. (2016). Dyscalculia and the calculating brain. Pediatric Neurology, 61, 11-20. https://doi.org/10.1016/j.pediatrneurol.2016.02.007

Revkin, S. K., Piazza, M., Izard, V., Cohen, L. \& Dehaene, S. (2008). Does subitizing reflect numerical estimation? Psychological Science, 19(6), 607-614. https://doi.org/10.1111/j.14679280.2008.02130.x

Schneider, M., Beeres, K., Coban, L., Merz, S., Schmidt, S., Stricker, J. \& De Smedt, B. (2016). Associations of nonsymbolic and symbolic numerical magnitude processing with mathematical competence: a meta-analysis. Developmental Science, 20(3), 1-16. http://doi. org/10.1111/desc.12372

Siemann, J. \& Petermann, F. (2018). Innate or Acquired? Disentangling number sense and early number competencies. Frontiers in Psychology, 9, 1-13. https:// doi.org/10.3389/fpsyg.2018.00571

Spelke, E. S. (2017). Core Knowledge, Language, and Number. Language Learning and Development, 13(2), 147-170, https://doi.org/10.1080/15475441.2016. 1263572 
Szkudlarek, E. \& Brannon, E. M. (2017). Does the approximate number system serve as a foundation for symbolic mathematics? Language learning and development: the official journal of the Society for Language Development, 13(2), 171-190. https://doi.org/10.1080/ 15475441.2016.1263573

Träff, L. O., Östergren, R. \& Skagerlund, K. (2020). Development of early domain-specific and domain-general cognitive precursors of high and low math achievers in grade 6. Child Neuropsychology, 26(8), 1065-1090. https://doi. org/10.1080/09297049.2020.1739259

Vanbinst, K., Ghesquiere, P. \& De Smedt, B. (2012). Numerical magnitude representations and individual differences in children's arithmetic strategy use. Mind, Brain, and Education, 6(3), 129-136. https://doi.org/10.1111/j.1751228X.2012.01148.x
Xenidou-Dervou, I., Van Luit, J. E. H., Kroesbergen, E. H., Friso-van den Bos, I., Jonkman, L. M., Van der Schoot, M. \& Van Lieshout, E. (2018). Cognitive predictors of children's development in mathematics achievement: a latent growth modeling approach. Developmental Science, 21(6), 1-51. https://doi. org/10.1111/desc.12671

Zhou, X., Wei, W., Zhang, Y., Cui, J. \& Chen, C. (2015). Visual perception can account for the close relation between numerosity processing and computational fluency. Frontiers in Psychology, 6, 1-13. https://doi.org/10.3389/ fpsyg.2015.01364

Sandra Torresi: Degree in Social Sciences (Universidad de Buenos Aires, Buenos Aires) 